Tropical Journal of Pharmaceutical Research October 2018; 17 (10): 2079-2086

ISSN: $1596-5996$ (print); 1596-9827 (electronic)

(c) Pharmacotherapy Group, Faculty of Pharmacy, University of Benin, Benin City, 300001 Nigeria.

Original Research Article

http://dx.doi.org/10.4314/tjpr.v17i10.27

\title{
Healthcare professionals' consensus on prescribing errors in hospital settings in Riyadh, Saudi Arabia
}

\author{
Mansour Adam Mahmoud ${ }^{1 *}$, Mohamed Azmi Hassali ${ }^{2}$, Hisham Aljadhey ${ }^{3}$, Sultan \\ Saad Al Thagfan ${ }^{1}$ \\ ${ }^{1}$ College of Pharmacy, Department of Clinical and Hospital Pharmacy, Taibah University, PO Box 344, Alamadinah \\ Almunawarah, 30001, Saudi Arabia, ${ }^{2}$ Discipline of Social and Administrative Pharmacy, School of Pharmaceutical Sciences, \\ Universiti Sains Malaysia, Penang, Malaysia, ${ }^{3}$ Saudi Food and Drug Authority, Riyadh, Saudi Arabia
}

*For correspondence: Email: mammm.99@gmail.com

Sent for review: 23 March 2018

Revised accepted: 21 September 2018

\begin{abstract}
Purpose: To create a consensus on definition and scenarios of prescribing errors in Saudi Arabia hospital practice.

Methods: A two-round Delphi technique was used to reach a consensus on a definition and 42 scenarios of prescribing errors. Thirty-five evaluators (healthcare professionals) were asked to indicate the extent to which they agree or disagree with the definition and scenarios of prescribing errors in a score of 1 ("total disagreement") to 9 ("total agreement") and were given a space to comment or modify the content of the survey.

Results: The study tool was initially given to 35 evaluators of whom 31 (88.6 \%) responded in the first round. In the second round only 24 (77.4\%) evaluators responded. A consensus was reached to accept the definition of prescribing error modified from a previous study conducted in the UK. Regarding the types of prescribing errors, a consensus was reached to include 34 scenarios, to exclude 5 scenarios and to include 3 scenarios depending on the individual clinical situation.

Conclusion: The evaluators agreed to the definition of prescribing errors developed in the United Kingdom (UK) with minor modifications. However, some types of prescribing errors might be considered as errors in Saudi Arabia but not in the UK and vice versa. It is anticipated that this definition could be utilized in future studies, particularly in Saudi Arabia, and act as a guide for future research on prescribing errors.
\end{abstract}

Keywords: Prescribing error scenario, Hospital settings, Consensus, Delphi technique

\begin{abstract}
This is an Open Access article that uses a funding model which does not charge readers or their institutions for access and distributed under the terms of the Creative Commons Attribution License (http://creativecommons.org/licenses/by/4.0) and the Budapest Open Access Initiative (http://www.budapestopenaccessinitiative.org/read), which permit unrestricted use, distribution, and reproduction in any medium, provided the original work is properly credited.

Tropical Journal of Pharmaceutical Research is indexed by Science Citation Index (SciSearch), Scopus, International Pharmaceutical Abstract, Chemical Abstracts, Embase, Index Copernicus, EBSCO, African Index Medicus, JournalSeek, Journal Citation Reports/Science Edition, Directory of Open Access Journals (DOAJ), African Journal Online, Bioline International, Open-J-Gate and Pharmacy Abstracts
\end{abstract}

\section{INTRODUCTION}

Prescription in the majority of the hospitals in Saudi Arabia are handwritten which may increase the risk to prescribing errors. The design of paper-based prescriptions varies between different hospitals in their content and are usually incomplete and do not comply with the standards of ideal prescriptions such as missing the patient allergy status [1]. Even in the cases where all necessary information is given in the prescription template, physicians may not always comply to fill all the necessary fields 
including important information such as age of patient [2]. Furthermore, the use of prohibited abbreviations in the prescription is also common among physicians [3].

Previous studies that investigated prescribing errors in Saudi Arabia lack a consistent and validated definition of prescribing errors [4,5]. Therefore, a clear definition and a standardized list of prescribing error situations should be developed to be used in practice and research as well. One of the widely used definitions is the definition developed in the United Kingdom (UK) [6]. This definition has been used by several studies [7]. However, to determine whether this definition is suitable for use in the Saudi Arabian hospital settings it is necessary to seek opinions of healthcare practitioners with expertise in medication safety and quality improvement practicing in the hospital setting within Saudi Arabia. This study aims to arrive on a consensus on the definition of prescribing errors through a Delphi process that involves healthcare practitioners with expertise in medication safety and quality management from different hospitals. This definition will guide other researchers in the future to investigate the prevalence and incidence of prescribing errors in the hospital setting.

\section{METHODS}

\section{Pilot study}

Before conducting the Delphi process, a pilot study was conducted to determine the suitability of the use of the prescribing errors definition and 42 scenarios developed in the UK [6]. Dean et al [6] defined prescribing errors as " $A$ clinically meaningful prescribing error occurs when, as a result of a prescribing decision or prescription writing process, there is an unintentional significant (1) reduction in the probability of treatment being timely and effective or (2) increase in the risk of harm when compared with generally accepted practice" [6]

The pilot study was conducted with a nephrologist, a head nurse and three clinical pharmacists to assess the suitability of the original definition and 42 prescribing error scenarios developed by Dean and colleagues of University College London for application in the hospital setting in Saudi Arabia [6]. The five healthcare professionals were purposively selected from different specialties with expertise in medication safety and quality improvement. Along with this definition healthcare professionals were asked to indicate the extent to which they agreed or disagreed with the definition on a scale of 1 (total disagreement) to 9 (total agreement) and were given an optional space to comment on or suggest a new definition or improve the given one. They were also asked to indicate the degree to which they believed that each of the 42 scenarios represented a prescribing error on a scale of 1 (definitely not an error) to 9 (definitely an error) accompanied with an optional comment. The study flow chart is illustrated in Figure 1.

\section{Pilot study results}

During the pilot study, the evaluators agreed with the definition but made several comments. They agreed with the concept of the definition, but they wanted a simpler and easier to understand definition. They viewed the definition as complicated because of possible language barriers. One reviewer suggested revising the definition by adding 'and' to 'or' (i.e., and/or) where both reduction in the treatment effectiveness and increase in the risk occurred. Another researcher suggested using another definition of prescribing errors suggested by the American Society of Hospital Pharmacists [8]. Taking into consideration the healthcare professionals comments and additional review of the literature it was decided to adopt the following definition: "A clinically meaningful prescribing error occurs when, as a result of a prescribing decision or prescription writing process, there is an unintentional significant: reduction in the probability of treatment being timely and effective and/or increase in the risk of harm to the patient compared to the generally accepted practice".

Based on the recommendations and comments from the pilot study it was necessary to make some minor and some major changes to few scenarios. For example, minor changes included using synonyms to make the scenarios easy to understand. Major changes include adding specific references that are widely used as drug information resources in Saudi hospitals and based on which dosage adjustments could be made. These include the Sanford Guide to antibiotic Therapy [9], the Drug Information Handbook [10] Micromedex [11], or the British National Formulary (BNF) [12].

\section{Delphi process}

A two round Delphi process was used to validate the definition and scenarios suggested by the pilot study. The study flow chart is illustrated in Figure 1. The Research and Ethics Committee at the School of Pharmacy, King Saud University approved the study. 


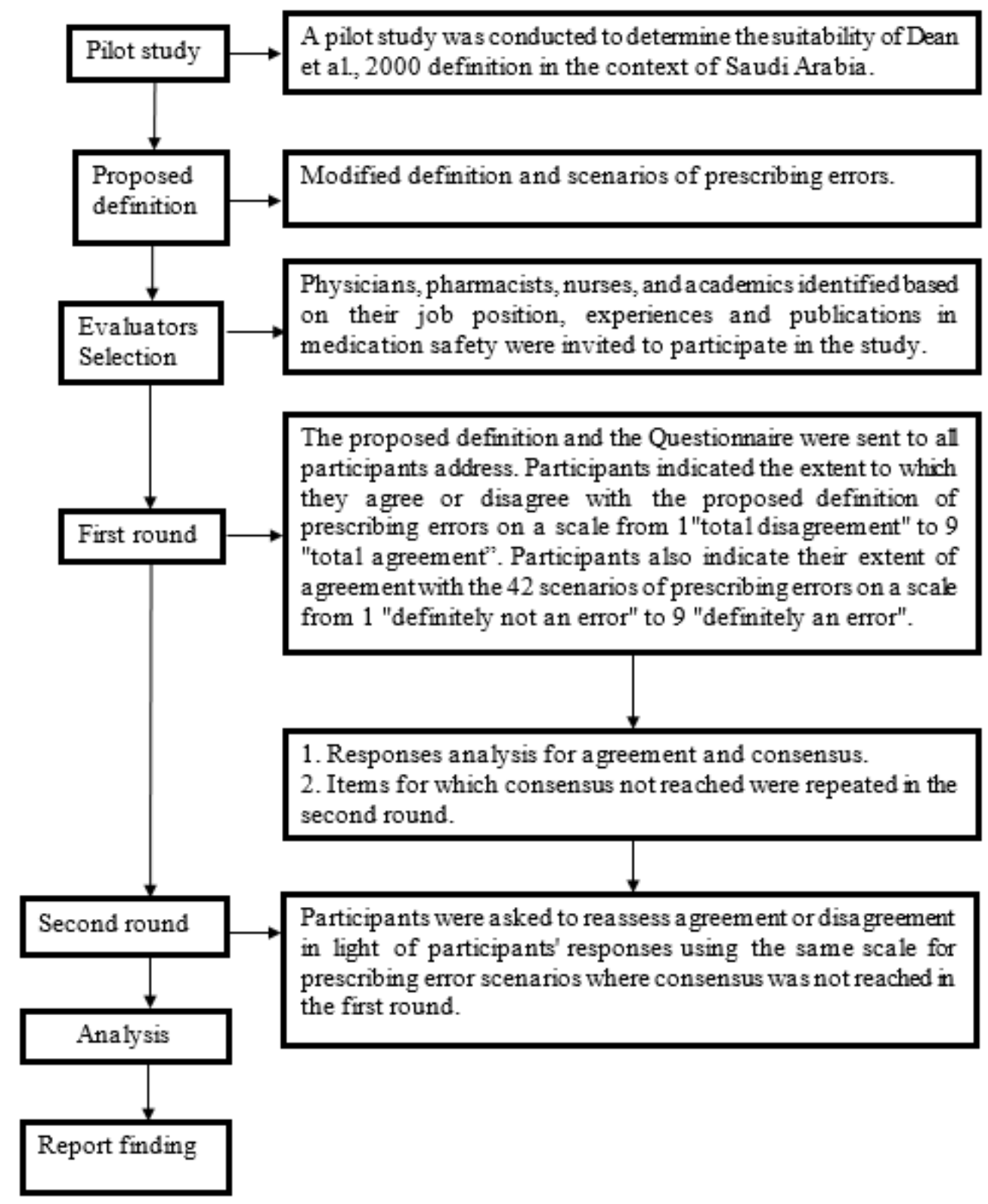

Figure 1: Study flow chart

\section{Selection of the evaluators:}

To obtain reliable result professionals with relevant experience in the area under investigation were selected to participate in the study. There is no standard list of criteria in the literature concerning the selection of Delphi process participants [13]. However, investigators should make sure that the selected participants have relevant background, qualification and experience on the topic and able to contribute with helpful information and don't mind revising their initial judgment until consensus is reached. In addition, the Delphi process subjects should be highly trained and competent in their area of expertise. Ways to find experts in the area of research are; review of publication related to the topic and people in top positions in institutions related to the study area. All these recommendations were considered while selecting potential expert' evaluators for the current study.

Non-probability sampling techniques such as purposive sampling or criterion sampling can be used in Delphi process [14]. In the current study a purposive sampling technique was employed. Thirty-five healthcare professionals were purposively selected from different hospitals using the previously mentioned criteria of expert selection. Invitations to participate in the study were sent through email or extended through telephone contact. Those who participated in the pilot study were not invited to participate in the Delphi process study. Healthcare professionals 
who accepted to participate were asked to sign a consent form.

\section{Data collection method}

Multiple rounds are conducted during the Delphi process. In a classical Delphi process the first round begins with an open-ended questionnaire [15]. After the first-round responses are received, the collected information can be converted into a well-structured questionnaire. This questionnaire is used as the survey instrument for the second round of data collection. However, it is also common and acceptable practice to use a structured questionnaire in the first round based on an extensive literature review [16]. The second round involves giving each evaluator a questionnaire that includes the items as well as the ratings summarized by the investigators in the earlier round and are asked to revise their judgments or to write the reasons for disagreement with other evaluators. This round gives the Delphi process evaluators a chance to make further clarifications of both, the information and their judgments of the relative importance of the items. However, compared to the earlier round, only a small increase in the degree of consensus can be expected. The number of rounds required to reach consensus depend on the amount and of number of questions, time available, and levels of sample fatigue. Although a classical process may take up to four rounds recent studies support having two rounds [6,17]. This study used a structured questionnaire as data collection instrument in the first round. Consensus was reached after conducting two rounds.

\section{First round}

In the first round of the Delphi process the questionnaire that was modified in the pilot study was sent to the evaluator's address by the researcher. The evaluators were reminded to complete and return the questionnaire by means of email or telephone calls from time to time. The same scaling used in the pilot study was also used in the Delphi study. Responses from the first round were analyzed and the median and IQR of each item was calculated.

\section{Second round}

In the second round the items on which consensus were not reached during the first round were sent again to the evaluators. The second version of the questionnaire included the median and IQR of each item, evaluators' responses and their anonymous comments. The evaluators were asked to review their responses having seen other evaluators' responses.

\section{Feedback and consensus}

Consensus is the level of agreement between participants in a particular round. Both qualitative and quantitative method can be used to provide feedback about each round. If quantitative approach is used feedback can be done by either providing percentages of participants sharing the same idea or by calculating the median score and the IQR to determine a cut-off point of agreement [18,13]. The IQR is a measure of dispersion for the median and consists of the middle $50 \%$ of the observations. In case qualitative approach is used the panel, responses can be summarized using content analysis to identify common themes for feedback [18]. Both quantitative and qualitative methods can be used together to supply the panel with numerical and qualitative data. An ordinal scoring system of items was used in the current study. The IQR and median was used to define consensus. A summary of the evaluators' comments were also provided in the second round.

\section{Selection of the evaluators}

Thirty five healthcare professionals were purposively selected from different hospitals and invited to participate in the study.

\section{Data analysis}

"Consensus" was considered to exist if the interquartile range of the evaluators' responses fell within any three point range $(1-9)$. "Disagreement" existed if the interquartile range spanned both the $1-3$ range and the $7-9$ range. If neither consensus nor disagreement existed, "partial agreement" was believed to have occurred. In the case of consensus, it was considered that the scenario should be included as a prescribing error if the median score fell within the $7-9$ range, that it should be excluded if it fell within the $1-3$ range, and that it was equivocal if it fell within the $4-6$ range. Where the consensus was that a scenario was equivocal, or where no consensus was obtained at the end of the second round, the evaluators' comments, together with their scores, were used to decide whether or not to classify each scenario as a prescribing error.

\section{RESULTS}

\section{Respondents' and their characteristics}


All 35 evaluators who were invited accepted to participate in the study. Of the 35 evaluators approached four did not respond to the questionnaire in the first round. The majority of respondents in the first round were clinical pharmacists 10 (32.2\%), followed by registrars 6 (19.4\%) and consultants 5 (16.1\%) (Table 1).

Table 1: Profession of evaluators and responses

\begin{tabular}{lcc}
\hline Profession & $\begin{array}{c}\text { Respondents in } \\
\text { the first } \\
\text { round (N=31) } \\
\mathbf{N}(\%)\end{array}$ & $\begin{array}{c}\text { Respondents } \\
\text { in the second } \\
\text { round (N=24) } \\
\mathbf{N}(\%)\end{array}$ \\
\hline $\begin{array}{l}\text { Consultants } \\
\text { Senior }\end{array}$ & $5(16.1)$ & $3(12.5)$ \\
registrars & $2(6.5)$ & $2(8.3)$ \\
$\begin{array}{l}\text { Registrars } \\
\text { Clinical }\end{array}$ & $6(19.4)$ & $4(16.7)$ \\
pharmacists & $10(32.2)$ & $8(33.3)$ \\
$\begin{array}{l}\text { Senior clinical } \\
\text { pharmacists }\end{array}$ & $4(12.9)$ & $4(16.7)$ \\
Head nurses & $3(9.7)$ & $2(8.3)$ \\
$\begin{array}{l}\text { Senior } \\
\text { pharmacologist }\end{array}$ & $1(3.2)$ & $1(4.2)$ \\
\hline
\end{tabular}

However in the second round only 24 out of the 31 evaluators responded. Non-respondents were two consultants, a hematologist, an oncologist, two registrars, two clinical pharmacists from critical care, and one internal medicine head nurse (Table 2).

Table 2: Specialties of evaluators and responses

\begin{tabular}{|c|c|c|}
\hline Specialties & $\begin{array}{c}\text { Respondents } \\
\text { in the first } \\
\text { round }(\mathrm{N}=31) \\
N(\%)\end{array}$ & $\begin{array}{c}\text { Respondents } \\
\text { in the second } \\
\text { round }(\mathrm{N}=24) \\
N(\%)\end{array}$ \\
\hline $\begin{array}{l}\text { Internal } \\
\text { medicine }\end{array}$ & $4(13)$ & $3(12.5)$ \\
\hline Critical care & $12(38.7)$ & $8(33.3)$ \\
\hline Cardiology & $2(6.5)$ & $2(8.3)$ \\
\hline Pulmonology & $1(3.2)$ & $1(4.2)$ \\
\hline Family medicine & $1(3.2)$ & $1(4.2)$ \\
\hline $\begin{array}{l}\text { Hematology } \\
\text { medicine }\end{array}$ & $1(3.2)$ & 0 \\
\hline Oncology & $1(3.2)$ & 0 \\
\hline $\begin{array}{l}\text { Obstetrics and } \\
\text { Gynecology }\end{array}$ & $1(3.2)$ & $1(4.2)$ \\
\hline $\begin{array}{l}\text { Emergency } \\
\text { Medicine }\end{array}$ & $1(3.2)$ & $1(4.2)$ \\
\hline $\begin{array}{l}\text { Paediatric } \\
\text { Cardiology }\end{array}$ & $1(3.2)$ & $1(4.2)$ \\
\hline Quality members & $4(13)$ & $4(16.6)$ \\
\hline Ambulatory care & $1(3.2)$ & $1(4.2)$ \\
\hline Pharmacology & $1(3.2)$ & $1(4.2)$ \\
\hline
\end{tabular}

Evaluators were selected from different specialties who also had a special interest in medication safety and quality management. Six clinical pharmacists and two consultants were involved in a study of medication errors at the time of conducting this study. The senior pharmacologist had extensive experience in research and publishing. Other evaluators were selected based on their practical experience with medication errors and quality improvement roles in their hospitals.

\section{First round}

A definition of prescribing errors and the 42 scenarios that were modified in the pilot study from those developed in a previous study were included in the questionnaire to be rated by the evaluators. In the first round consensus was reached to include $23(54.8 \%)$ scenarios as prescribing errors. Therefore, it was necessary to include 19 scenarios for which consensus was not reached in the second round along with the median and interquartile range of each item, evaluators responses and their anonymous comments.

\section{Second Round}

Of the 19 scenarios included in the second round, consensus was reached to include 11 scenarios, partial agreement to exclude two scenarios and six scenarios were partially agreed on to be equivocal. For the latter six scenarios, the evaluators' comments were reviewed and it was decided to exclude three events that were considered equivocal in the first and the second rounds and determined that the other three events might be considered prescribing errors depending on the individual clinical situation. Finally, consensus was reached to include 34 events as prescribing errors (Table 3), three events were considered errors depending on the individual clinical situation (Table 4) and five events were excluded (Table 5).

\section{DISCUSSION}

The evaluators agreed that the definition could be used to detect prescribing errors within the inpatient hospital settings in Saudi Arabia. In addition, the specific scenarios where an event can be considered as a prescribing error were also agreed on. The use of consensus method to develop a definition of prescribing errors has been criticized [19]. In fact the consensus methods used added validity to the result and avoid many problems associated with committeebased decision making. Others also argued that the definition ignored prescribing errors that do not result in harm, however the current definition does not exclude errors that result in harm rather it includes clinically meaningful errors [20]. 
It was found that the evaluators agreed with the definition and suggested some minor changes.

However, there were differences in terms of

Table 3: Situations that should be included as prescribing errors

\begin{tabular}{|c|c|c|c|}
\hline Scenario & $\begin{array}{c}\text { First } \\
\text { round* }\end{array}$ & $\begin{array}{l}\text { Second } \\
\text { round* }\end{array}$ & Code $^{\mathrm{a}}$ \\
\hline Prescribing a drug that is contraindicated for a due to co-existing clinical condition & $8,9,9$ & - & $\mathrm{C}, \mathrm{I}$ \\
\hline $\begin{array}{l}\text { Prescription of a drug to which the patient has a documented clinically significant } \\
\text { allergy }\end{array}$ & $9,9,9$ & - & C,I \\
\hline Not considering a potentially significant drug interaction & $7,8,9$ & - & C,I \\
\hline $\begin{array}{l}\text { Prescribing a drug in a dose that, according to nationally and internationally } \\
\text { accepted references (Sanford Guide to antibiotic Therapy or Drug Information } \\
\text { Handbook or Micromedex or BNF) is inappropriate for a patient's renal function }\end{array}$ & $8,9,9$ & - & C,I \\
\hline $\begin{array}{l}\text { Prescribing a drug in a dose below that recommended for the patient's clinical } \\
\text { condition }\end{array}$ & $6.5,8,9$ & $7,8,9$ & $\mathrm{C}, \mathrm{I}$ \\
\hline $\begin{array}{l}\text { Prescribing a drug with a narrow therapeutic index, in a dose predicted or } \\
\text { expected to give serum levels significantly above the desired therapeutic range }\end{array}$ & $7,9,9$ & - & C,I \\
\hline $\begin{array}{l}\text { Writing a prescription for a drug with a narrow therapeutic range in a dose } \\
\text { predicted or expected to give serum levels significantly below the desired } \\
\text { therapeutic range }\end{array}$ & $7,8,9$ & - & C,I \\
\hline $\begin{array}{l}\text { Not changing the dose for a patient following steady state serum levels } \\
\text { significantly outside the therapeutic range }\end{array}$ & $8,9,9$ & - & $\mathrm{C}, \mathrm{I}$ \\
\hline $\begin{array}{l}\text { Continuing a drug in the event of a clinically significant adverse drug reaction } \\
\text { (ADR) }\end{array}$ & $8.5,9,9$ & - & $\mathrm{C}, \mathrm{I}$ \\
\hline $\begin{array}{l}\text { Prescribing two drugs for the same indication when only one of the drugs is } \\
\text { necessary }\end{array}$ & $6.5,9,9$ & $7,9,9$ & C,I \\
\hline Prescribing a drug for which there is no indication for that patient & $8,9,9$ & - & $\mathrm{C}, \mathrm{I}$ \\
\hline $\begin{array}{l}\text { Prescribing a drug to be given by intravenous infusion in a diluent that is } \\
\text { incompatible with the drug prescribed }\end{array}$ & $9,9,9$ & - & C,I \\
\hline $\begin{array}{l}\text { Prescribing a drug to be infused via an intravenous peripheral line, in a } \\
\text { concentration greater than that recommended for peripheral administration }\end{array}$ & $7,9,9$ & - & C,I \\
\hline Prescribing a drug, dose, or route that is not that intended & $8.5,9,9$ & - & $\mathrm{C}, \mathrm{I}$ \\
\hline Writing illegibly (example, unclear handwriting) & $6.5,8,9$ & $7,8,9$ & $\mathrm{C}, \mathrm{I}$ \\
\hline Writing a drug's name using abbreviations or other non-standard nomenclature & $6,8,9$ & $7,9,9$ & C,I \\
\hline Writing an ambiguous medication order & $5.5,8,9$ & $7,9,9$ & C,I \\
\hline $\begin{array}{l}\text { Prescribing as "one tablet" of a drug that is available in more than one strength of } \\
\text { tablet }\end{array}$ & $7,9,9$ & - & C,I \\
\hline $\begin{array}{l}\text { Omission of the route of administration for a drug that can be given by more than } \\
\text { one route }\end{array}$ & $7,9,9$ & - & $\mathrm{C}, \mathrm{I}$ \\
\hline $\begin{array}{l}\text { Prescribing a drug to be given by intermittent intravenous infusion, without } \\
\text { specifying the duration over which it is to be infused }\end{array}$ & $7,9,9$ & - & $\mathrm{C}, \mathrm{I}$ \\
\hline Omission of the prescriber's signature & $5.5,7,9$ & $6.5,9,9$ & $\mathrm{P}, \mathrm{I}$ \\
\hline $\begin{array}{l}\text { On admission to hospital, unintentionally not prescribing a drug that the patient } \\
\text { was taking prior to his/her admission }\end{array}$ & $4.5,7,9$ & $6,9,9$ & $\mathrm{P}, \mathrm{I}$ \\
\hline $\begin{array}{l}\text { Continuing a general practitioners prescribing errors when writing a patient's drug } \\
\text { chart on admission to hospital }\end{array}$ & $7,9,9$ & - & $\mathrm{C}, \mathrm{I}$ \\
\hline Transcribing a medication order incorrectly when rewriting a patient's drug chart & $7,9,9$ & - & C,I \\
\hline Writing "milligrams" "when microgram" was intended. & $9,9,9$ & - & $\mathrm{C}, \mathrm{I}$ \\
\hline $\begin{array}{l}\text { Writing a prescription for discharge drug that unintentionally deviates from the } \\
\text { drug prescribed on the inpatient drug chart }\end{array}$ & $8,9,9$ & - & C,I \\
\hline $\begin{array}{l}\text { On admission to hospital, writing a drug order that unintentionally deviates from } \\
\text { the patient's pre-admission prescription }\end{array}$ & $6,7,9$ & $7,9,9$ & $\mathrm{C}, \mathrm{I}$ \\
\hline $\begin{array}{l}\text { Prescribing a drug without informing the patient of its uses and potential side } \\
\text { effects }\end{array}$ & $4.5,7,8.5$ & $4,7,8$ & $\mathrm{P}, \mathrm{I}$ \\
\hline $\begin{array}{l}\text { Prescribing a drug in a dose above the maximum dose recommended in the } \\
\text { national and internationally accepted references (Sanford Guide to antibiotic } \\
\text { Therapy or Drug Information Handbook or Micromedex or BNF) }\end{array}$ & $6,8,9$ & $7,8,9$ & C,I \\
\hline $\begin{array}{l}\text { Prescribing a dose that cannot readily be administered using the dosage forms } \\
\text { available }\end{array}$ & $4.5,6,8$ & $5,7,9$ & $\mathrm{P}, \mathrm{I}$ \\
\hline $\begin{array}{l}\text { Prescribing a dose regime (dose/frequency) that is not that recommended for the } \\
\text { formulation prescribed }\end{array}$ & $7,9,9$ & - & $\mathrm{C}, \mathrm{I}$ \\
\hline Continuing a prescription for a longer duration than necessary & $7,8,9$ & - & C,I \\
\hline $\begin{array}{l}\text { Prescribing a drug that should be given at specific times in relation to meals } \\
\text { without specifying this information on the prescription }\end{array}$ & $7,7,8.5$ & - & C,I \\
\hline $\begin{array}{l}\text { Unintentionally not prescribing a drug for a clinical condition for which medication } \\
\text { is indicated }\end{array}$ & $7,8,9$ & - & $\mathrm{C}, \mathrm{I}$ \\
\hline
\end{tabular}


*The lower limit of the interquartile range, the median and the upper limit of the interquartile range. a $\mathrm{C}=$ consensus; $\mathrm{P}=\mathrm{Partial} ; \mathrm{I}=$ Include prescribing error

Table 4: Situations that should be included as prescribing errors depending on the individual clinical situation

\begin{tabular}{|c|c|c|c|}
\hline Scenario & First round* & $\begin{array}{l}\text { Second } \\
\text { round }\end{array}$ & Code $^{a}$ \\
\hline $\begin{array}{l}\text { Prescribing for an indication that is not a drug's product license } \\
\text { Misspelling a drug name }\end{array}$ & $\begin{array}{l}3,6,7.5 \\
4.5,7,9\end{array}$ & $\begin{array}{c}3.5,6,7 \\
5,7,9\end{array}$ & $\begin{array}{l}P, E Q \\
P, E Q\end{array}$ \\
\hline $\begin{array}{l}\text { Prescribing a drug for a child that has no product license for use in } \\
\text { children }\end{array}$ & $6,8,9$ & $5.5,6,9$ & $P, E Q$ \\
\hline
\end{tabular}

Table 5: Situations that should be excluded as prescribing errors

\begin{tabular}{|c|c|c|c|}
\hline Variable & First round $^{\star}$ & Second round ${ }^{\star}$ & $\underset{\text { Code }}{\text { Code }}$ \\
\hline $\begin{array}{l}\text { Prescribing a drug for which there is no evidence of efficacy, because } \\
\text { the patient wishes it }\end{array}$ & $5,4,9$ & $3.5,3,9$ & $P, E X$ \\
\hline Prescribing a drug that is not in the hospital formulary & $1,3,5$ & $1,2,5$ & $P, E X$ \\
\hline Prescribing contrary to national treatment guidelines & $5,7,8.5$ & $4,6,8$ & $P, E Q$ \\
\hline Prescribing by brand name (as opposed to generic name) & $2,5,7.5$ & $1.5,5,7.5$ & $P, E Q$ \\
\hline Prescribing contrary to hospital treatment guidelines & $3.5,6,9$ & $3,5,9$ & $P, E Q$ \\
\hline
\end{tabular}

${ }^{*}$ The lower limit of the interquartile range, the median and the upper limit of the interquartile range. ${ }^{a} \mathrm{P}=\mathrm{Partial}$; $\mathrm{EX}=$ Exclude; $\mathrm{EQ}=$ Equivocal

which prescribing error scenarios should be included or excluded. In particular, all scenarios included as prescribing errors in the previous study by Dean et al [6] were also included as errors by the evaluators. However, in contrast to Dean and colleagues one scenario which was excluded by them and six scenarios that were considered equivocal were included as prescribing errors in this study. Regarding a scenario that was excluded by Dean and colleagues and included in the current study (prescribing a drug without informing the patient of its uses and potential side effects) the evaluators considered that the patient must be informed about the side effects of their medications because then they will not be worried when they happen after taking the medication. Also, patients must know which disease they are taking their medicine for, because this will probably help them to adhere to their medications. Examples of scenarios that were included by the evaluators and considered equivocal by Dean and colleagues included, continuing a prescription for a longer duration than necessary [6].

The evaluators considered this scenario as a prescribing error in order to avoid unnecessary side effects when the patients do not need the particular drug any more. They also considered that information related to meals and medication administration time must be specified in the prescription; otherwise they should be considered as a prescribing error. One of the evaluators commented that it may lead to underdosing, especially if the drug is an antibiotic, because this may predispose the patient to resistance. Scenarios related to adherence to hospital or national treatment guidelines and prescribing by brand names were excluded. Hospitals and national treatment guidelines in Saudi Arabia can sometimes be outdated and the evaluators panel preferred to follow current advances in treatments. Among the excluded scenarios, prescribing according to patient preference was also present because patients are not aware of the efficacy of their treatments.

Three scenarios were considered prescribing errors depending on the individual clinical situation. One of these was prescribing for an indication that is not included in a drug's product license. Our evaluators indicated that this can be an error if clinical studies did not prove the drug's effectiveness. The second scenario was misspelling a drug name. This was considered a prescribing error if the drug name could not be read at all. A third scenario was prescribing a drug to a child for which there is no product license for children. This would not be considered as an error if clinical studies proved its effectiveness for the disease for which it has been prescribed and if there is no alternative drug for the particular disease.

\section{Limitations of the study}

This study has some limitations. Firstly, it is quite difficult to generalize the study result to all healthcare professionals in Saudi Arabia. However, the study findings could be similar in other cities of Saudi Arabia because the practice 
is not much different between cities, but it could be different in rural areas. Secondly, Delphi technique is time-consuming because it involves more than one round of questions and as always anticipated, physicians often lack time to answer questions more than once. Thus, it was obvious that some practitioners did not answer the questions in the second round.

\section{CONCLUSION}

The evaluators in Saudi Arabia agreed with the definition of prescribing errors developed in the UK with minor modifications. However, agreements on the scenarios were different from the UK study. Some scenarios might be considered prescribing errors in Saudi Arabia but not in the UK and vice versa. It is hoped that this definition would be utilized in future studies, particularly in Saudi Arabia, and act as a guide for future research on prescribing errors.

\section{DECLARATIONS}

\section{Acknowledgement}

We would like to thank all evaluators who gave their opinion in this study. We would also like to thank managements of the hospitals involved for giving approval to conduct this study.

\section{Conflict of interest}

The authors declare that no conflict of interest with regard to this work.

\section{Authors' contribution}

We declare that this work was done by the authors named in this article and all liabilities pertaining to claims relating to the content of this article will be borne by the authors. MA designed the study, conducted the study and wrote the first draft of the manuscript. All authors contributed in manuscript writing and review.

\section{REFERENCES}

1. Aljadhey H, Mahmoud MA, Mayet A, Alshaikh M, Ahmed $Y$, Murray $M D$, Bates $D W$. Incidence of adverse drug events in an academic hospital: a prospective cohort study. Int J Qual Health Care 2013; 25: 648-655

2. Albarrak Al, Al Rashidi E A, Fatani R K, Al Ageel Sl, Mohammed R.. Assessment of legibility and completeness of handwritten and electronic prescriptions. Saudi Pharm J. 2014; 22(6), 522-527.
3. Alshaikh M, Mayet A, Adam M, Ahmed Y, Aljadhey $H$. Intervention to reduce the use of unsafe abbreviations in a teaching hospital. Saudi Pharm J 2013; 21(3), 277280.

4. Al-Dhawailie A. Inpatient prescribing errors and pharmacist intervention at a teaching hospital in Saudi Arabia. Saudi Pharm J2011; 19: 193-196.

5. Al-Jeraisy $M$, Alanazi $M$, Abolfotouh $M$. Medication prescribing errors in a pediatric inpatient tertiary care setting in Saudi Arabia. BMC Res Notes 2011; 4: 294. doi: 10.1186/1756-0500-4-294.

6. Dean B, Barber N, Schachter M. What is a prescribing error? Qual Health Care 2000; 9: 232-237.

7. Lewis PJ, Dornan T, Taylor D, Tully MP, Wass V, Ashcroft DM. Prevalence, incidence and nature of prescribing errors in hospital inpatients. Drug Saf 2009; 32: $379-389$

8. American Society of Hospital Pharmacists. ASHP Guidelines on preventing medication errors in hospitals. Am J Hosp Pharm 1993; 50: 305-14

9. Gilbert DN, Moellering RC, Eliopoulos GM, Chambers $H F$, Saag MS. The Sanford Guide to Antimicrobial Therapy 2010. 40th ed. Antimicrobial Therapy, Inc, Sperryville, VA; 2010

10. Lacy CF, Armstrong LL, Goldman MP, Lance LL. Drug Information Handbook, 20th ed. Hudson, Ohio, LexiComp, Inc.; 2011: 1143-7.

11. Micromedex Healthcare Series. DRUGDEX System. Greenwood Village, CO: Truven Health Analytics, 2013.

12. British Medical Association and the Royal Pharmaceutical Society of Great Britain. British National Formulary. 58th ed. UK: BMJ Publishing Group. 2009.

13. Hill KQ, Fowles J. The methodological worth of the Delphi forecasting technique. Technological Forecasting and Social Change; 1975; 7, 179-192.

14. Hasson F, Keeney S, McKenna H. Research guidelines for the Delphi survey technique. J Adv Nurs 2000; 32(4), 1008-1015.

15. Keeney S, Hasson F, McKenna H. The Delphi Technique in Nursing and Health Researchn 2011; Willy Online Library.

16. Hsu C, Sandford B (2007). The Delphi Technique: Making Sense of Consensus. Practical Assessment, Research \& Evaluation 2007; 12(10), 1531-7714

17. Ghaleb MA, Barber N, Dean B, Wong K. What constitutes a prescribing error in paediatrics? Qual Saf Health Care, 2012; 14(5), 352-357.

18. Cantrill JA, Sibbald B, Buetow S. The Delphi and nominal group techniques in health services research. Int $J$ Pharm Pract1996; 4: 2:67-74

19. Ferner RE. The epidemiology of medication errors: the methodological difficulties. Br J Clin Pharmacol 2009, 67(6), 614-620.

20. Aronson JK. Medication errors: definitions and classification. Br J Clin Pharmacol 2009, 67(6), 599-604. 